SOUZA, Fernando Machado de e CHUEIRI, Miriam Fecchio. Controle judicial do orçamento público para efetivação de direitos fundamentais. Revista Eletrônica Direito e Política, Programa de PósGraduação Stricto Sensu em Ciência Jurídica da UNIVALI, Itajaí, v.10, n.3, 2o quadrimestre de 2015. Disponível em: www.univali.br/direitoepolitica - ISSN 1980-7791.

\title{
CONTROLE JUDICIAL DO ORÇAMENTO PÚBLICO PARA EFETIVAÇÃO DE DIREITOS FUNDAMENTAIS
}

\author{
CONTROLE JUDICIAL DEL PROGRAMA ORÇAMENTARIO PUBLICO PARA LA \\ EFECTIVACIÓN DE LOS DERECHOS FUNDAMENTALES
}

\author{
Fernando Machado de Souza ${ }^{1}$ \\ Miriam Fecchio Chueiri ${ }^{2}$
}

\begin{abstract}
SUMÁRIO: Introdução; 1. Discricionariedade Administrativa; 2. Acórdão em análise; 3. Separação dos poderes; 4. Efetivação dos direitos fundamentais; 5. Dignidade da pessoa humana; 6. Mínimo existencial e reserva do possível; 7. Orçamento público; 8. Vetores hermenêuticos para invalidar decisões políticas inconstitucionais; 9. Ponderação entre princípios constitucionais; Considerações Finais; Referências das Fontes Citadas.
\end{abstract}

\section{RESUMO}

o presente artigo trata do controle judicial das políticas públicas assecuratórias de direitos fundamentais, por meio do controle do Orçamento Público. Tendo em vista que o Estado Democrático de Direito deve pautar sua atuação administrativa visando o atendimento das necessidades públicas, é necessária a ponderação entre os postulados básicos da dignidade da pessoa humana e da autonomia constitucional dos Poderes do Estado, nas decisões em o Judiciário vincule a atuação do administrador para garantir o acesso aos direitos fundamentais.

PALAVRAS-CHAVE: Controle Judicial; Efetividade; Políticas Públicas; Direitos Fundamentais.

\section{RESUMEN}

El presente artículo trata del control judicial de las políticas públicas garantidoras de los derechos fundamentales, por médio del controle del presupuesto del gobierno. Teniendo en cuenta que el Estado Democrático del Derecho deve atentar su atuación com la finalidad del atendimiento de los servicios públicos, es preciso la ponderación entre los postulados de la dignidad humana y de la

\footnotetext{
${ }^{1}$ Mestrando Em Direito Processual e Cidadania pela UNIPAR. Professor e advogado.

2 Professora do Programa de Mestrado em Direito Processual e Cidadania da UNIPAR
} 
SOUZA, Fernando Machado de e CHUEIRI, Miriam Fecchio. Controle judicial do orçamento público para efetivação de direitos fundamentais. Revista Eletrônica Direito e Política, Programa de PósGraduação Stricto Sensu em Ciência Jurídica da UNIVALI, Itajaí, v.10, n.3, 2o quadrimestre de 2015. Disponível em: www.univali.br/direitoepolitica - ISSN 1980-7791.

autonomía constitucional de los Poderes del Estado, en las decisiones de los jueces que enlace la atuación del administrador para alcanzar los derechos fundamentales.

PALABRAS-ClAVe: Controle Judicial; Efetividad; Politicas Publicas; Derechos Fundamentales.

\section{INTRODUÇÃO}

O art. $2^{\circ}$ da Constituição Federal estabelece os Poderes constitutivos da União em Legislativo, Executivo e Judiciário. Seja através da leitura clássica de Montesquieu, seja pelas atuais teorias de freios e contrapesos, sinteticamente se distinguem uma função típica para cada Poder, passível, no entanto, do estabelecimento de mecanismos de controle pelos demais.

No que se refere ao controle judicial da Administração Pública, reputa-se incontroversa a fiscalização dos atos administrativos quanto aos aspectos de legalidade ou desvio de finalidade.

Segundo Bandeira de Mello "assim como ao Judiciário compete fulminar todo comportamento ilegítimo da Administração que apareça como frontal violação da ordem jurídica, compete-lhe igualmente, fulminar qualquer comportamento administrativo que, a pretexto de exercer apreciação ou decisão discricionária, ultrapassar as fronteiras dela". ${ }^{3}$

Tal concepção impede que o Judiciário adentre o denominado mérito administrativo, concebido como um instituto jurídico oriundo da discricionariedade e inerente à atividade do Administrador Público.

Entretanto, tendo por base o cumprimento dos ideais do Estado Democrático de Direito, é necessário delimitar a responsabilidade do Poder Público, bem como os critérios interpretativos para invalidação das políticas públicas incompatíveis com a Constituição.

\footnotetext{
${ }^{3}$ MELLO, C. A. B. de. Curso de Direito Administrativo. 31. ed. rev e atual. São Paulo: Malheiros, 2013. p. 997.
} 
SOUZA, Fernando Machado de e CHUEIRI, Miriam Fecchio. Controle judicial do orçamento público para efetivação de direitos fundamentais. Revista Eletrônica Direito e Política, Programa de PósGraduação Stricto Sensu em Ciência Jurídica da UNIVALI, Itajaí, v.10, n.3, 2o quadrimestre de 2015. Disponível em: www.univali.br/direitoepolitica - ISSN 1980-7791.

\section{DISCRICIONARIEDADE ADMINISTRATIVA}

Sobre a discricionariedade administrativa, estabelece Bandeira de Mello, que esta é a margem de liberdade que defere ao administrador, a possibilidade de eleger, segundo critérios consistentes de razoabilidade, um, dentre pelo menos dois comportamentos cabíveis perante o caso concreto. Ressalta o autor que o norte da atuação discricionária é o cumprimento do dever de adotar à satisfação da finalidade legal "quando por força da fluidez das expressões da lei ou da liberdade conferida no mandamento, dela não se possa extrair objetivamente uma solução unívoca para a situação vertente". ${ }^{4}$

Cabe ao Poder Judiciário, como forma de fiscalização ao poder do Executivo, exercer por meio da inafastabilidade da tutela jurisdicional, o controle externo sobre os atos da Administração, que se desviarem das finalidades vinculadas pela lei ou mesmo que extrapolarem os contornos delineados por esta nos atos discricionários.

Portanto, justamente nos "casos que comportam discrição administrativa que o socorro do Judiciário ganha foros de remédio mais valioso, mais ambicionado e mais necessário para os jurisdicionados, já que a pronúncia representa a garantia última para a contenção do administrador dentro dos limites de liberdade efetivamente conferidos pelo sistema normativo." 5

Nessa linha, Alvim entende que o controle judicial deve ter como limitador a observância do mérito administrativo, sendo este, afeto tão somente ao Administrador Público. In verbis, "a generalidade de nossa doutrina, bem como de nossa jurisprudência, entende que, conquanto os atos administrativos estejam submetidos ao controle do Judiciário, o mérito de tais atos é insuscetível de ser reexaminado, dado que constitui assunto exclusivamente afeto à Administração Pública. Desta afirmação, ipso facto, conclui-se que o Judiciário

\footnotetext{
${ }^{4}$ MELLO, C. A. B. de. Curso de Direito Administrativo. 31. ed. rev e atual. São Paulo: Malheiros, 2013. p. 991.

${ }^{5}$ MELLO, C. A. B. de. Curso de Direito Administrativo. - 31. ed. rev e atual. - São Paulo: Malheiros, 2013. p. 1009-10.
} 
SOUZA, Fernando Machado de e CHUEIRI, Miriam Fecchio. Controle judicial do orçamento público para efetivação de direitos fundamentais. Revista Eletrônica Direito e Política, Programa de PósGraduação Stricto Sensu em Ciência Jurídica da UNIVALI, Itajaí, v.10, n.3, 2o quadrimestre de 2015. Disponível em: www.univali.br/direitoepolitica - ISSN 1980-7791.

pode tão-somente examinar o aspecto da legalidade do ato administrativo. A afirmação é exata e recolhe seu fundamento primário e constitucional na própria separação de poderes (art. $2 .^{\circ}$ da CF), no sentido e com a função de que a cada "poder" está afeta uma determinada função, sem ingerência dos outros". 6

Em defesa do controle judicial da atuação administrativa, afirma Chiovenda que "frente a los órganos administrativos esta fiscalización jurisidicional considérase por la moderna doctrina como el médio más eficaz para mantener la actividad adminsitrativa dentro de los limites de la ley. Esta fiscalización puede ser indirecta, como cuando el juez penal examina si uma orden de la autoridad administrativa fué dada legalmente para castigar o no castigar al contraventor. Pero puede ser directa com cuando se impugna directamente ante la autoridad jurisdicional (ordinária o especial) el acto administrativo". ${ }^{7}$

Entretanto, o ato administrativo não deve se limitar somente ao cumprimento da lei em sentido formal. A atuação administrativa deve ser voltada para o pleno atendimento da finalidade precípua da Administração, qual seja, a satisfação das necessidades públicas.

\section{ACÓRDÃO EM ANÁLISE}

Nesse aspecto, o presente artigo visa analisar se a interferência do Poder Judiciário que visa a implementação de políticas públicas garantidoras da dignidade da pessoa humana, viola o princípio da separação dos poderes.

"EMENTA DiREITO CONSTITUCIONAL. AÇÃO CIVIL PÚBLICA. DEFENSORIA PÚBLICA. AMPLIAÇÃO DA ATUAÇÃO. OMISSÃO DO ESTADO QUE FRUSTA DIREITOS FUNDAMENTAIS. IMPLEMENTAÇÃO DE POLÍTICAS PÚBLICAS. CONTROLE JURISDICIONAL. POSSIBILIDADE. PRINCÍPIO DA SEPARAÇÃO DOS

\footnotetext{
${ }^{6}$ ALVIM, A., 1936. Manual de direito processual civil, volume 1 : arte geral / Arruda Alvim. 12. p. 213

7 CHIOVEndA, J. Derecho Procesal Civil. Principios. - Tijuana : Cardenas Editor y Distribuidor, 1989. p. 380.
} 
SOUZA, Fernando Machado de e CHUEIRI, Miriam Fecchio. Controle judicial do orçamento público para efetivação de direitos fundamentais. Revista Eletrônica Direito e Política, Programa de PósGraduação Stricto Sensu em Ciência Jurídica da UNIVALI, Itajaí, v.10, n.3, 2o quadrimestre de 2015. Disponível em: www.univali.br/direitoepolitica - ISSN 1980-7791.

PODERES. OFENSA NÃO CONFIGURADA. ACÓRDÃO RECORRIDO PUBLICADO EM 22.10.2007. Emerge do acórdão que ensejou o manejo do recurso extraordinário que o Tribunal a quo manteve a sentença que condenou o Estado a designar um defensor público para prestar serviços de assistência jurídica gratuita aos hipossuficientes da Comarca de Demerval Lobão consoante os arts. 50, LXXIV, 127, caput, 129, III e IX e 134 da Constituição Federal. No caso de descumprimento da obrigação, fixou multa diária. O acórdão recorrido não divergiu da jurisprudência da Suprema Corte no sentido de que é lícito ao Poder Judiciário, em face do princípio da supremacia da Constituição, em situações excepcionais, determinar que a Administração Pública adote medidas assecuratórias de direitos constitucionalmente reconhecidos como essenciais, sem que isso configure violação do princípio da separação dos Poderes. Precedentes. O exame da legalidade dos atos administrativos pelo Poder Judiciário não ofende o princípio da separação dos Poderes. Precedentes. Agravo regimental conhecido e não provido." ${ }^{8}$

Trata-se de decisão em agravo regimental, julgado pela $1^{\text {a }}$ Turma do Supremo Tribunal Federal, interposto pelo estado do Piauí, contra decisão que manteve a condenação para obrigar o ente federativo a designar um defensor público para prestar assistência judiciária na comarca de Demerval Lobão.

Como estabelece a Constituição federal em seu art. 134: "A Defensoria Pública é instituição permanente, essencial à função jurisdicional do Estado, incumbindoIhe, como expressão e instrumento do regime democrático, fundamentalmente, a orientação jurídica, a promoção dos direitos humanos e a defesa, em todos os graus, judicial e extrajudicial, dos direitos individuais e coletivos, de forma integral e gratuita, aos necessitados, na forma do inciso LXXIV do art. $5^{\circ}$ desta Constituição Federal. ${ }^{9}$

8 BRASIL. AI 739151 AgR, Relator(a): Min. ROSA WEBER, Primeira Turma, julgado em 27/05/2014, ACÓRDÃO ELETRÔNICO DJe-112 DIVULG 10-06-2014 PUBLIC 11-06-2014

9 BRASIL, CONSTITUIÇÃO. Constituição da República Federativa do Brasil. Promulgada em 8 de outubro de 1988. < http://www.planalto.gov.br/ccivil_03/constituicao/constituicao.htm>, acesso em 12 de agosto de 2014. 
SOUZA, Fernando Machado de e CHUEIRI, Miriam Fecchio. Controle judicial do orçamento público para efetivação de direitos fundamentais. Revista Eletrônica Direito e Política, Programa de PósGraduação Stricto Sensu em Ciência Jurídica da UNIVALI, Itajaí, v.10, n.3, 2o quadrimestre de 2015. Disponível em: www.univali.br/direitoepolitica - ISSN 1980-7791.

No mesmo sentido, dispõe a Lei Complementar 132/2009, que regulamenta a atuação da Defensoria Pública da União, e estabelece normas gerais para funcionamento e atuação da mesma em âmbito federal e nos estados. ${ }^{10}$

Cabe aqui, singela consideração acerca do município de Demerval Lobão, epicentro da decisão judicial que alcançou a Corte Superior.

Localizado no Piauí, o município conta com 13.496 habitantes, segundo dados do Instituto Brasileiro de Geografia e Estatística (IBGE), relativos ao ano de 2013. O Índice de Desenvolvimento Humano do Município é de 0,618, valor abaixo da modesta média brasileira de 0,744. O município dispõe de 4 estabelecimentos de saúde, sendo 3 públicos, e uma população de analfabetos correspondente a 4.205 pessoas (aproximadamente $30 \%$ do contingente populacional). ${ }^{11}$

Acrescenta-se ao panorama descrito, a inexistência de Defensoria Pública instalada na comarca, conforme informações da página eletrônica da Defensoria Pública do Estado do Piauí. (http://www.defensoria.pi.gov.br/enderecos-etelefones) $)^{12}$

O principal fundamento da insurgência do Estado do Piuaí contra a decisão judicial, é a violação da separação dos poderes prevista na Constituição Federal, motivada pela ingerência do Poder Judiciário em atividade competência do Poder Executivo.

Tem entendido o Judiciário, por meio de recente jurisprudência, que não se incorre em ofensa à Constituição, a decisão judicial que determina a efetivação de direitos fundamentais, quando prejudicados por omissão específica do Estado. No presente caso, entendeu a Corte que a ausência de assistência judiciária

\footnotetext{
10 BRASIL, Lei Complementar n. 132. Altera dispositivos da Lei Complementar n 80, de 12 de janeiro de 1994, que organiza a Defensoria Pública da União, do Distrito Federal e dos Territórios e prescreve normas gerais para sua organização nos Estados, e da Lei no 1.060, de 5 de fevereiro de 1950, e dá outras providências. <http://www.planalto.gov.br/ccivil_03/leis/lcp/Lcp132.htm>, acesso em 12 de agosto de 2014.

${ }^{11}$ Instituto Brasileiro de Geografia e Estatística. http://cidades.ibge.gov.br/xtras/temas.php?lang =\&codmun=220330\&idtema $=16 \&$ search $=|| \mathrm{s} \% \mathrm{E}$ Dntese-das-informa\%E7\%F5es, acesso em 15 de agosto de 2014.

12 Defensoria Pública do Estado do Piauí. <http://www.defensoria.pi.gov.br/enderecos-etelefones>, acesso em 15 de agosto de 2014.
} 
SOUZA, Fernando Machado de e CHUEIRI, Miriam Fecchio. Controle judicial do orçamento público para efetivação de direitos fundamentais. Revista Eletrônica Direito e Política, Programa de PósGraduação Stricto Sensu em Ciência Jurídica da UNIVALI, Itajaí, v.10, n.3, 2o quadrimestre de 2015. Disponível em: www.univali.br/direitoepolitica - ISSN 1980-7791.

gratuita aos que necessitados na comarca, representa violação ao dispositivo constitucional correspondente.

Observa-se, portanto, o conflito entre dois princípios inerentes ao estado Democrático de Direito: a separação dos Poderes e a Dignidade da Pessoa Humana, representada aqui pela obstrução do acesso à Justiça.

\section{SEPARAÇÃO DOS PODERES}

Como dito nas linhas iniciais, a República Federativa do Brasil, constitui-se de um Estado Democrático de Direito, tripartido em Poderes independentes e harmônicos entre si, quais sejam, o Legislativo, o Executivo e o Judiciário.

Na concepção clássica, a tripartição dos Poderes do Estado em funções distintas impede que haja a concentração de Poder, que poderia levar o detentor a cometer abusos contra o a liberdade individual.

Nessa perspectiva, a separação dos Poderes pode ser entendida como um dos conceitos basilares do constitucionalismo moderno, estando na origem da liberdade individual e do Estado de Direito. ${ }^{13}$

Segundo Barroso, "o conteúdo nuclear e histórico do princípio da separação dos Poderes pode ser descrito nos seguintes termos: as funções estatais devem ser divididas e atribuídas a órgãos diversos e devem existir mecanismos de controle recíproco entre eles, de modo a proteger os indivíduos contra o abuso potencial de um poder absoluto". ${ }^{14}$

Pode-se estabelecer, em que pese a complexidade da sistemática constitucional brasileira, a distribuição das competências do Estado em administrativa,

\footnotetext{
${ }^{13}$ BARROSO, L. R. Curso de direito constitucional contemporâneo. 3 ed. São Paulo: Saraiva, 2011. p. 196.

${ }^{14}$ BARROSO, L. R. Curso de direito constitucional contemporâneo. 3 ed. São Paulo : Saraiva, 2011.
} 
SOUZA, Fernando Machado de e CHUEIRI, Miriam Fecchio. Controle judicial do orçamento público para efetivação de direitos fundamentais. Revista Eletrônica Direito e Política, Programa de PósGraduação Stricto Sensu em Ciência Jurídica da UNIVALI, Itajaí, v.10, n.3, 2o quadrimestre de 2015. Disponível em: www.univali.br/direitoepolitica - ISSN 1980-7791.

jurisdicional e legislativa, que são tidas como as funções típicas. Tais funções são atribuídas entre os Poderes Executivo, Judiciário e Legislativo, respectivamente.

Entretanto, são admitidos mecanismos hábeis a manter os Poderes em equilíbrio, por meio de medidas pontuais que assegurem o controle externo dos demais Poderes. Tais mecanismos são denominados de freios e contrapesos.

São exemplos constitucionais de intervenção legítima de um Poder em outro, o julgamento do Presidente da República pelo Senado, nos crimes de responsabilidade (Art. 52, X), a fiscalização do orçamento pelo Tribunal de Contas, a indicação pelo Presidente da República, dos Ministros dos Tribunais Superiores, dentre outros.

\section{EFETIVAÇÃO DOS DIREITOS FUNDAMENTAIS}

Interessa ao presente trabalho, sobretudo, os direitos definidos como de segunda dimensão, ou direitos sociais, como sendo aqueles que exigem uma prestação positiva do Estado. A análise dos direitos prestacionais se dá em decorrência da própria natureza dos direitos fundamentais objeto de políticas públicas de Governo, de modo que não merece, no momento, grande atenção à mera preservação das liberdades individuais.

Como diferencia Marinoni, "os direitos fundamentais foram vistos, à época do constitucionalismo de matriz liberal-burguesa, apenas como o direito de o particular impedir a ingerência do Poder Público em sua esfera jurídica, ou seja, como direitos de defesa. Contudo, o que importa, aqui, são os chamados direitos a prestações, ligados às novas funções do Estado diante da sociedade". ${ }^{15}$

15 MARINONI, L. G. Técnica processual e tutela dos direitos. 2 ed. ver. e atual. São Paulo: Editora Revista dos Tribunais, 2008. p. 133. 
SOUZA, Fernando Machado de e CHUEIRI, Miriam Fecchio. Controle judicial do orçamento público para efetivação de direitos fundamentais. Revista Eletrônica Direito e Política, Programa de PósGraduação Stricto Sensu em Ciência Jurídica da UNIVALI, Itajaí, v.10, n.3, 2o quadrimestre de 2015. Disponível em: www.univali.br/direitoepolitica - ISSN 1980-7791.

Partindo dessa premissa, enquanto os direitos de defesa das liberdades individuais limitam o poder estatal, os direitos sociais reclamam uma crescente atuação ativa do Estado na execução de obrigações positivas. ${ }^{16}$

A eficácia dos direitos fundamentais possui efeito irradiante no ordenamento jurídico, servindo como farol da atuação estatal, tanto na elaboração das normas, da aplicação, bem como de sua interpretação, sendo que "a norma de direito fundamental, independentemente da possibilidade de sua subjetivação, sempre contém valoração. O valor nela contido, revelado de modo objetivo, espraia-se necessariamente sobre a compreensão e a atuação do ordenamento jurídico. Atribui-se aos direitos fundamentais, assim, uma eficácia irradiante. ${ }^{17}$

Pode-se falar na eficácia dos direitos fundamentais na dimensão objetiva e subjetiva, quando consideradas as relações entre o Poder Público e os particulares ou as relações entre particulares. ${ }^{18}$

Quanto à eficácia objetiva das normas que tratam de direitos fundamentais, destaca-se como uma das mais importantes consequências desta dimensão, o dever do Estado em conferir proteção aos direitos fundamentais. ${ }^{19}$

Prossegue Marinoni, concluindo que as normas consagradoras de direitos fundamentais afirmam valores, os quais incidem sobre a totalidade do ordenamento jurídico e servem para iluminar as tarefas dos órgãos judiciários, legislativos e executivos. Nesse sentido, é possível dizer que tais normas implicam uma valoração de ordem objetiva. ${ }^{20}$

Como determina Cambi, a efetivação dos direitos fundamentais sociais depende de políticas públicas capazes de aplicar, adequadamente, todos os recursos públicos disponíveis para a maior promoção dos valores essenciais dos seres

${ }^{16}$ SARLET, I. W. A eficácia dos direitos fundamentais. 6 ed. rev. Atual. E amp. - Porto Alegre : Livraria do Advogado, 2006. p. 296.

17 MARINONI, L. G. Técnica processual e tutela dos direitos. 2 ed. ver. e atual. São Paulo: Editora Revista dos Tribunais, 2008. p. 132.

18 MARINONI, L. G. Técnica processual e tutela dos direitos. 2 ed. ver. e atual. São Paulo: Editora Revista dos Tribunais, 2008. p. 133.

19 MARINONI, L. G. Técnica processual e tutela dos direitos. 2 ed. ver. e atual. São Paulo: Editora Revista dos Tribunais, 2008. p. 132.

20 MARINONI, L. G. Técnica processual e tutela dos direitos. 2 ed. ver. e atual. São Paulo: Editora Revista dos Tribunais, 2008. p. 132. 
SOUZA, Fernando Machado de e CHUEIRI, Miriam Fecchio. Controle judicial do orçamento público para efetivação de direitos fundamentais. Revista Eletrônica Direito e Política, Programa de PósGraduação Stricto Sensu em Ciência Jurídica da UNIVALI, Itajaí, v.10, n.3, 2o quadrimestre de 2015. Disponível em: www.univali.br/direitoepolitica - ISSN 1980-7791.

humanos. Na mesma linha, deve-se atentar para a observância dos valores decorrentes da dignidade da pessoa humana, que constitui a premissa antropológica do Estado Democrático de Direito, previsto no art. $1^{\circ}$, III, da Constituição Federal. ${ }^{21}$

A busca pela efetivação dos direitos fundamentais constitui o vetor hermenêutico da atuação administrativa, sobretudo no que concerne aos direitos prestacionais de segunda geração, como saúde, educação, e demais direitos sociais.

Fica evidente que quando se refere à efetivação de políticas públicas, o controle judicial não recai sobre uma ilegalidade do Poder Pública, e sim sobre uma omissão específica que frustra direitos fundamentais.

Em se tratando de omissão do Estado administrador, o Judiciário não emite somente um juízo de valor acerca de algum ato praticado, mas obriga o Estado a adotar determinada medida, que mais se coadune com o caso concreto.

Posto isso, surge a discussão acerca da eventual ingerência do Poder Judiciário, em competência exclusiva do Poder Executivo, onde o Estado se esquiva da implementação de determinadas políticas de acesso à direitos, sob alegação de atendimento à "reserva do possível", enquanto o Judiciário pleiteia a efetivação do "mínimo existencial".

\section{DIGNIDADE DA PESSOA HUMANA}

Como leciona Barroso, a dignidade da pessoa humana identifica um espaço de integridade a ser assegurada a todas as pessoas por só sua existência no mundo. A dignidade relaciona-se tanto com a liberdade e valores espirituais, quanto com as condições materiais de sobrevivência digna. ${ }^{22}$

${ }^{21}$ CAMBI, E. A. S. Neoconstitucionalismo e Neoprocessualismo. 2 ed. Revista dos Tribunais: 2012. p. 418.

22 BARROSO, L. R. Curso de direito constitucional contemporâneo. 3 ed. São Paulo: Saraiva, 2011. p. 274. 
SOUZA, Fernando Machado de e CHUEIRI, Miriam Fecchio. Controle judicial do orçamento público para efetivação de direitos fundamentais. Revista Eletrônica Direito e Política, Programa de PósGraduação Stricto Sensu em Ciência Jurídica da UNIVALI, Itajaí, v.10, n.3, 2o quadrimestre de 2015. Disponível em: www.univali.br/direitoepolitica - ISSN 1980-7791.

Ao ser entendida a dignidade da pessoa humana, como a base dos direitos e garantias fundamentais, a mesma passa a orientar a atividade de integração normativa. No que se refere ao Estado, este princípio serve de baliza para a implementação de políticas públicas de viabilização dos direitos dele decorrentes. Como dignidade humana, pode-se "compreender a existência condigna não recaindo a esfera de proteção apenas sobre a mera sobrevivência fisiológica e psíquica da pessoa humana, mas também o livre desenvolvimento de sua personalidade e sua inclusão na sociedade". ${ }^{23}$

Imperioso destacar que a dignidade da pessoa humana, além de consistir em um dos princípios fundamentais do Estado Democrático de Direito, foi alçada à condição de finalidade precípua da ordem econômica, devendo, portanto, orientar a atividade do estado em todas as suas dimensões. ${ }^{24}$

\section{MÍNIMO EXISTENCIAL E RESERVA DO POSSÍVEL}

A partir do entendimento dos contornos da dignidade da pessoa humana, é possível sintetizar um núcleo básico de garantias como critério de medição do atendimento da dignidade humana. Esse núcleo fundamental é o denominado mínimo existencial.

Afirma Barroso, que o mínimo existencial é "uma locução que identifica um conjunto de bens e utilidades básicas para a subsistência física e indispensável ao desfrute dos direitos em geral". Acrescenta ainda que "aquém daquele patamar, ainda que haja sobrevivência, não há dignidade". ${ }^{25}$

Segundo o autor, o elenco de prestações definidas dentro do mínimo existencial varia conforme o sujeito destinatário, entretanto, existe razoável consenso, que o mínimo existencial não pode prescindir de saúde básica, renda mínima e

\footnotetext{
${ }^{23}$ CAMBI, E. A. S. Neoconstitucionalismo e Neoprocessualismo. 2 ed. Revista dos Tribunais: 2012. p. 415.

${ }^{24}$ SARLET, I. W. A eficácia dos direitos fundamentais. - 6 ed. rev. Atual. e amp. Porto Alegre: Livraria do Advogado, 2006. p. 327.

${ }^{25}$ CAMBI, E. A. S. Neoconstitucionalismo e Neoprocessualismo. 2 ed. Revista dos Tribunais: 2012. p. 275.
} 
SOUZA, Fernando Machado de e CHUEIRI, Miriam Fecchio. Controle judicial do orçamento público para efetivação de direitos fundamentais. Revista Eletrônica Direito e Política, Programa de PósGraduação Stricto Sensu em Ciência Jurídica da UNIVALI, Itajaí, v.10, n.3, 2o quadrimestre de 2015. Disponível em: www.univali.br/direitoepolitica - ISSN 1980-7791.

educação fundamental, além do elemento instrumental do acesso à Justiça como garantia de efetivação dos demais direitos. ${ }^{26}$

Pode-se acrescentar ainda, que as decisões do Poder Público que se omitem em alocar os recursos na efetivação dos direitos fundamentais, optando pela realização de outros fins constitucionalmente menos relevantes, criam sérios óbices à proteção do mínimo existencial. ${ }^{27}$

Em contraponto ao conjunto básico de direitos aos quais devem ser assegurados ao indivíduo, desenvolveu-se a chamada reserva do possível, como um limitador da atuação estatal de acordo com suas possibilidades econômico, financeira e estruturais. De acordo com esse entendimento, ao Estado cabe a decisão acerca da melhor destinação dos recursos disponíveis, cabendo aos seus órgãos políticos a eleição das necessidades mais urgentes.

A reserva do possível, porém, não pode ser usada como subterfúgio para que o Poder Público não efetive direitos fundamentais, como se tal limitação fosse a justificativa para a ineficiência do serviço público. Esse é entendimento do Supremo Tribunal Federal, afastando a aplicação da reserva do possível em casos de violação de direito constitucionalmente assegurado, a saber:

"APELAÇÕES CÍVEIS. INTERNAÇÃO COMPULSÓRIA CONTRA DROGADIÇÃO. ANTECIPAÇÃO DE TUTELA. DIREITO CONSTITUCIONALMENTE GARANTIDO. RESPONSABILIDADE DOS ENTES PÚBLICOS. ILEGITIMIDADE AFASTADA. INAPLICABILIDADE DA RESERVA DO POSSÍVEL NA HIPÓTESE. MANTIDA A PROCEDÊNCIA DA AÇÃO, NÃO CONHECIDO O REEXAME NECESSÁRIO. APELOS DESPROVIDOS.". 28

${ }^{26}$ CAMBI, E. A. S. Neoconstitucionalismo e Neoprocessualismo. 2 ed. Revista dos Tribunais: 2012. p. 275.

27 CAMBI, E. A. S. Neoconstitucionalismo e Neoprocessualismo. 2 ed. Revista dos Tribunais: 2012. p. 421.

28 BRASIL. Apelação e Reexame Necessário No 70058249905, Sétima Câmara Cível, Tribunal de Justiça do RS, Relator: Sandra Brisolara Medeiros, Julgado em 24/07/2014) (TJ-RS - REEX: 70058249905 RS, Relator: Sandra Brisolara Medeiros, Data de Julgamento: 24/07/2014, Sétima Câmara Cível, Data de Publicação: Diário da Justiça do dia 29/07/2014. Disponível em: JUSBRASIL. $\quad$ http://tj-rs.jusbrasil.com.br/jurisprudencia/130203540/apelacao-e-reexamenecessario-reex-70058249905-rs/inteiro-teor-130203550, acesso em 16 de agosto de 2014. 
SOUZA, Fernando Machado de e CHUEIRI, Miriam Fecchio. Controle judicial do orçamento público para efetivação de direitos fundamentais. Revista Eletrônica Direito e Política, Programa de PósGraduação Stricto Sensu em Ciência Jurídica da UNIVALI, Itajaí, v.10, n.3, 2o quadrimestre de 2015. Disponível em: www.univali.br/direitoepolitica - ISSN 1980-7791.

Em que pese tal limitação não possa ser utilizada de forma deliberada como obstáculo à efetivação das necessidades básicas, tal fundamentação é facilmente encontrada na ampla maioria das contestações apresentadas pelos advogados públicos, nas lides que envolvem obrigação de fazer e que tem o Estado como réu. ${ }^{29}$

\section{ORÇAMENTO PÚBLICO}

A competência para proposição das leis orçamentárias cabe ao Poder Executivo, como dispõe o art. 165 da Constituição Federal. Por meio dos instrumentos orçamentários, plano plurianual, diretrizes orçamentárias e orçamentos anuais, o Estado planeja seus investimentos nas mais variadas frentes de atuação pública.

O orçamento público, formalmente consolidado na Inglaterra no século início do século XIX, tem como escopo primordial o controle sobre os gastos do Executivo. Sua origem remonta à necessidade controlar as despesas do Estado Liberal, de modo a evitar o crescimento dos gastos públicos.

A partir do século XX, com o declínio do Estado Liberal e desenvolvimento das bases do Estado do bem-estar social, o orçamento, antes um mero instrumento de previsão de receitas e despesas passou a se consolidar como meio de planejamento e execução de políticas de correção das distorções sociais. ${ }^{30}$

Segundo define Giacomoni, "a viabilização dos projetos estratégicos e, consequentemente, dos grandes objetivos e metas fica possibilitada pela adoção de políticas básicas que condicionarão as ações e decisões dos setores público e privado." 31

${ }^{29}$ CAMBI, E. A. S. Neoconstitucionalismo e Neoprocessualismo. 2 ed. Revista dos Tribunais: 2012. p. 430.

${ }^{30}$ GIACOMONI, J. Orçamento Público. 15. ed. ampl. rev. e atual. São Paulo: Atlas, 2010. p. 5457.

${ }^{31}$ GIACOMONI, J. Orçamento Público. 15. ed. ampl. rev. e atual. São Paulo: Atlas, 2010. p. 234. 
SOUZA, Fernando Machado de e CHUEIRI, Miriam Fecchio. Controle judicial do orçamento público para efetivação de direitos fundamentais. Revista Eletrônica Direito e Política, Programa de PósGraduação Stricto Sensu em Ciência Jurídica da UNIVALI, Itajaí, v.10, n.3, 2o quadrimestre de 2015. Disponível em: www.univali.br/direitoepolitica - ISSN 1980-7791.

Anualmente, o Poder Executivo encaminha ao Congresso Nacional (na esfera federal) o projeto da lei de diretrizes orçamentárias, que uma vez aprovada pelo parlamento, estabelece as metas e prioridades da atuação administrativa.

Nessa esteira, a norma ordinária de iniciativa do Executivo, legitimada pela regularidade da tramitação administrativa, estaria imune ao controle judicial, pois não apresentaria formalmente nenhuma ilegalidade passível de controle.

Entretanto, adotando-se a dignidade da pessoa humana como vetor hermenêutico para atuação estatal, o controle da Administração passa a ser passível da fiscalização não somente da legalidade, mas da própria fundamentalidade dos objetivos e ações propostas e executadas.

A gestão do orçamento público, não representa um fim em si mesmo, devendo servir aos interesses públicos, que por sua vez, correspondem ao atendimento das necessidades identificadas na coletividade.

Diante do extenso conjunto de atribuições econômicas e sociais imputadas ao Executivo, com a crescente necessidade de implementação de políticas públicas de distribuição de renda e redução da desigualdade social, devem ser ampliados os sistemas de controle orçamentário, tanto interno quanto externamente.

Chega-se a problemática de como promover a satisfação das ilimitadas necessidades públicas, que, à medida que a sociedade progride, se tornam mais complexas, com os limitados recursos financeiros obtidos pelo Estado na atividade tributária.

Por esse motivo, ganha cada vez mais importância, a concepção da eficiência no Serviço Público. O Estado eficiente na aplicação dos recursos públicos tem condições de auferir o máximo de ganho possível no atendimento das demandas básicas do indivíduo, empregando o mínimo possível de recursos.

Os serviços públicos devem adotar conceitos de rendimento, produtividade, planejamento e estratégia, visando a máxima eficácia do recurso aplicado, evitando com isso, o desperdício de verbas públicas. Afirma Cambi, "afinal, o desperdício de recursos, em um contexto de escassez, promove injustiças, 
SOUZA, Fernando Machado de e CHUEIRI, Miriam Fecchio. Controle judicial do orçamento público para efetivação de direitos fundamentais. Revista Eletrônica Direito e Política, Programa de PósGraduação Stricto Sensu em Ciência Jurídica da UNIVALI, Itajaí, v.10, n.3, 2o quadrimestre de 2015. Disponível em: www.univali.br/direitoepolitica - ISSN 1980-7791.

especialmente para as pessoas que potencialmente mais necessitam da prestação estatal". ${ }^{32}$

A Constituição Federal dispõe, expressamente, a eficiência como princípio norteador da Administração Pública, conforme art. 37, caput, vinculando a Administração a prestação de serviço eficaz, visando o atendimento pleno das necessidades públicas.

Pela perspectiva da máxima eficiência na implementação de políticas públicas assecuratórias de direitos fundamentais, compete ao Poder Judiciário, não obstante o controle interno (autotutela), o controle sobre os atos ineficazes na efetivação dos valores constitucionais.

Como disciplina Cambi, "compete ao Poder Judiciário invalidar decisões políticas incapazes de concretizar o valor jurídico da dignidade da pessoa humana, considerado em seu aspecto positivo e social, notadamente quando restar demonstrado que tais escolhas não asseguraram a proteção do mínimo existencial." ${ }^{33}$

Sendo o Poder Judiciário, detentor da competência de controlar os atos da Administração, e esta, estando vinculada à eficiência na prestação do serviço público, cabe ao Judiciário intervir nas decisões administrativas que violem tais preceitos, inclusive adentrando no mérito administrativo.

A possibilidade de análise do mérito do ato administrativo pelo Judiciário, hipótese rechaçada pela doutrina clássica administrativista, tem espaço nas hipóteses em que o gestor, amparado pela discricionariedade, deixa de adotar medidas que concretizem direitos fundamentais ou, ainda que adote, deixe de fazê-lo do modo mais eficiente. Nesse sentido: "O Estado Democrático de Direito não é capaz de promover a justiça social sem a eficiente formulação e execução de políticas públicas, voltadas à realização dos direitos fundamentais sociais. Assim sendo, cabe ao Judiciário examinar as razões de conveniência e

\footnotetext{
${ }^{32}$ CAMBI, E. A. S. Neoconstitucionalismo e Neoprocessualismo. 2 ed. - Revista dos Tribunais: 2012. p. 430.

33 CAMBI, E. A. S. Neoconstitucionalismo e Neoprocessualismo. 2 ed. - Revista dos Tribunais: 2012. p. 421.
} 
SOUZA, Fernando Machado de e CHUEIRI, Miriam Fecchio. Controle judicial do orçamento público para efetivação de direitos fundamentais. Revista Eletrônica Direito e Política, Programa de PósGraduação Stricto Sensu em Ciência Jurídica da UNIVALI, Itajaí, v.10, n.3, 2o quadrimestre de 2015. Disponível em: www.univali.br/direitoepolitica - ISSN 1980-7791.

oportunidade da Administração Pública quando as escolhas produzidas pelo administrador público não são as mais adequadas para a concretização da Constituição." 34

O orçamento representa o "momento máximo da cidadania", onde as escolhas são feitas e depois fiscalizadas. Entretanto, no exemplo brasileiro, pairam sérias desconfianças, em decorrência da obscuridade com que são definidas as metas e programas de governo, onde muitas vezes os interesses políticos, quando não meramente partidários, impõem a vinculação do orçamento a diretrizes de prioridade questionável. "As escolhas estatais devem ser as mais claras e transparentes possíveis, a fim de que se possa verificar se são justificáveis." ${ }^{135}$

\section{VETORES HERMENÊUTICOS PARA INVALIDAR DECISÕES POLÍtICAS INCONSTITUCIONAIS}

Os tratados de direito internacional pós Segunda Guerra, bem como, no Brasil, a Constituição Federal de 1988, elevaram à dignidade da pessoa a valor central do ordenamento jurídico constitucional. ${ }^{36}$

Tais normas representaram uma resposta ética às violações de direitos humanos, legitimadas por programas políticos de governos totalitários. Nas palavras de Cambi, "a ética dos direitos humanos está orientada pelo respeito à igualdade de cada um dos seres humanos, cujas potencialidades devem ser resguardadas, a fim de que se desenvolvam de forma livre, autônoma e plena. Com efeito, tal ética está assentada na afirmação da dignidade quanto na prevenção do sofrimento humano." ${ }^{37}$

34 CAMBI, E. A. S. Neoconstitucionalismo e Neoprocessualismo. 2 ed. - Revista dos Tribunais: 2012. p. 421.

${ }^{35}$ CAMBI, E. A. S. Neoconstitucionalismo e Neoprocessualismo. 2 ed. - Revista dos Tribunais: 2012. p. 425.

${ }^{36}$ CAMBI, E. A. S. Neoconstitucionalismo e Neoprocessualismo. 2 ed. - Revista dos Tribunais: 2012. p. 412.

37 CAMBI, E. A. S. Neoconstitucionalismo e Neoprocessualismo. 2 ed. - Revista dos Tribunais: 2012. p. 413. 
SOUZA, Fernando Machado de e CHUEIRI, Miriam Fecchio. Controle judicial do orçamento público para efetivação de direitos fundamentais. Revista Eletrônica Direito e Política, Programa de PósGraduação Stricto Sensu em Ciência Jurídica da UNIVALI, Itajaí, v.10, n.3, 2o quadrimestre de 2015. Disponível em: www.univali.br/direitoepolitica - ISSN 1980-7791.

Uma vez que a dignidade da pessoa humana ressoa unívoca nas constituições de grande parte dos regimes democráticos, resta ao Estado disponibilizar mecanismos para garantir a eficácia das normas programáticas.

Nesse ponto, o Poder Judiciário assume relevante importância, devendo a jurisdição ser um instrumento garantidor dos ideais do Estado democrático de Direito. Ensina Cambi, que a intervenção judicial na fiscalização de políticas públicas, depende da eleição de critérios interpretativos, pois "havendo mais de um modo de interpretar a Constituição, deve-se optar por aquele que melhor concretize o valor da dignidade da pessoa humana". Nesse passo, sempre que se descortinarem dois ou mais meios de interpretação, deve ser acolhido aquele que melhor integralize os pressupostos de tal valor jurídico supremo. ${ }^{38}$

Cabe ao Judiciário, enquanto fiscal dos atos do Executivo, não a substituição da avaliação da autoridade competente, mas o estabelecimento de critérios interpretativos, com vistas a assegurar a integral execução dos direitos fundamentais, abarcados pelos programas governamentais.

Nesse sentido, a atuação interventiva do Judiciário encontra respaldo na omissão do Executivo em prever políticas públicas de acesso a direitos fundamentais, na fase de elaboração do planejamento do ano seguinte, ou ainda, que, uma vez previsto, o Executivo deixe de implementá-lo em decorrência de ineficiência do aparato estatal.

Entretanto, não basta afirmar que o governo tem que atuar conforme os preceitos do Estado democrático, ou ainda que o Judiciário deve exercer rígido controle dos atos da Administração para efetivação das políticas sociais. Devem ser estabelecidos parâmetros racionais e razoáveis, para o que o Judiciário possa fazer cumprir suas decisões, "sob pena de se comprometer a sua autoridade, abrindo enorme margem de destruição do Estado Democrático de Direito." Prossegue o autor afirmando que, "evidenciado que o dinheiro público está sendo

38 CAMBI, E. A. S. Neoconstitucionalismo e Neoprocessualismo. 2 ed. - Revista dos Tribunais: 2012. p. 414. 
SOUZA, Fernando Machado de e CHUEIRI, Miriam Fecchio. Controle judicial do orçamento público para efetivação de direitos fundamentais. Revista Eletrônica Direito e Política, Programa de PósGraduação Stricto Sensu em Ciência Jurídica da UNIVALI, Itajaí, v.10, n.3, 2o quadrimestre de 2015. Disponível em: www.univali.br/direitoepolitica - ISSN 1980-7791.

utilizado indevidamente, frustrando a realização do mínimo existencial, o Judiciário poderá efetivar o direito fundamental violado." 39

\section{PONDERAÇÃO ENTRE PRINCÍPIOS CONSTITUCIONAIS}

A colisão de valores constitucionais tem se tornado tema recorrente em julgamentos nas Cortes superiores de estados democráticos, bem como tema de destacada atenção de doutrinas e debates jurídicos. Sobretudo após a segunda metade do século $X X$, as Constituições passaram a abrigar, tal qual um guardachuva, os mais variados valores e preceitos fundamentais. Em consequência da órbita de complexos valores sob o núcleo constitucional, verificam-se inevitáveis choques entre os mesmos.

Nesse passo, salienta Barroso que "a identificação e o equacionamento das colisões de normas constitucionais são relativamente recentes no direito contemporâneo. A complexidade e o pluralismo das sociedades modernas levaram ao abrigo da Constituição valores, interesses e direitos variados, que eventualmente entram em choque." ${ }^{40}$

Assim, classifica o mencionado autor, que 0 entrechoque de normas constitucionais é de três tipos: colisão entre princípios constitucionais, colisão entre direitos fundamentais e colisão entre direitos fundamentais e outros valores e interesses constitucionais. ${ }^{41}$

Embora coabitem o mesmo texto constitucional em harmonia abstrata, a aplicação dos direitos fundamentais no caso concreto pode acarretar atritos. Importante mencionar que os meios de superação de antinomia das normas

${ }^{39}$ CAMBI, E. A. S. Neoconstitucionalismo e Neoprocessualismo. 2 ed. - Revista dos Tribunais: 2012. p. 428.

${ }^{40}$ BARROSO, L. R. Curso de direito constitucional contemporâneo. 3 ed. São Paulo: Saraiva, 2011. p. 352.

${ }^{41}$ BARROSO, L. R. Curso de direito constitucional contemporâneo. 3 ed. São Paulo: Saraiva, 2011. p. 352. 
SOUZA, Fernando Machado de e CHUEIRI, Miriam Fecchio. Controle judicial do orçamento público para efetivação de direitos fundamentais. Revista Eletrônica Direito e Política, Programa de PósGraduação Stricto Sensu em Ciência Jurídica da UNIVALI, Itajaí, v.10, n.3, 2o quadrimestre de 2015. Disponível em: www.univali.br/direitoepolitica - ISSN 1980-7791.

ordinárias (especialidade, hierarquia e cronologia), não são capazes de equalizar valores constitucionais em rota de colisão.

A subsunção enquanto raciocínio padrão na aplicação do Direito, não cabe na ponderação entre princípios constitucionais. Entende-se por subsunção o método silogístico no qual a premissa maior, a norma, incide sobre a premissa menor, os fatos, para daí se extrair um resultado, no caso, a solução jurídica.

Insuficiente a tradicional subsunção como meio de enfrentamento dos conflitos normativo-constitucionais, foi necessário o desenvolvimento de outras técnicas de integração da Constituição. Nesse sentido, surge a ponderação, que consiste na incidência de uma ou mais normas constitucionais, em maior ou menor grau, de acordo com a especificidade do caso.

Barroso destaca três etapas da atividade ponderativa. Na primeira, se opera a seleção das normas ou princípios em conflito, aplicáveis ao caso concreto. No segundo momento, analisam-se as circunstâncias concretas que incidem sobre o fato analisado e sua interação com os elementos normativos. E na terceira etapa, se opera a principal diferenciação entre a subsunção e a ponderação. Na ponderação, por se tratar de equacionamento de princípios, poderá haver a incidência maior ou menor, de um ou de outro, sem que isso lhes retire a eficácia normativa. Como define o autor, nessa fase dedicada à decisão, os diferentes grupos de normas e a repercussão dos fatos do caso concreto estarão sendo examinados de forma conjunta, de modo a apurar os pesos que devem ser atribuídos aos diversos elementos em disputa e, portanto, o grupo de normas que deve preponderar no caso."42

Para tanto, deverá ser levado em consideração os princípios da proporcionalidade ou razoabilidade.

Ambos princípios, razoabilidade e proporcionalidade, oferecem meios para que o intérprete faça concessões recíprocas entre os valores em disputa, preservando o

42 BARROSO, L. R. Curso de direito constitucional contemporâneo. 3 ed. São Paulo: Saraiva, 2011. p. 359. 
SOUZA, Fernando Machado de e CHUEIRI, Miriam Fecchio. Controle judicial do orçamento público para efetivação de direitos fundamentais. Revista Eletrônica Direito e Política, Programa de PósGraduação Stricto Sensu em Ciência Jurídica da UNIVALI, Itajaí, v.10, n.3, 2o quadrimestre de 2015. Disponível em: www.univali.br/direitoepolitica - ISSN 1980-7791.

máximo o conteúdo das normas em questão, ainda que em caso de incompatibilidade, um deles seja excluído momentaneamente. ${ }^{43}$

No acórdão analisado, colidiram dois dos principais pressupostos do Estado Democrático de Direito: a separação dos Poderes institucionais e a dignidade da pessoa humana. Aplicando-se o método da ponderação de princípios no presente caso, de acordo com as etapas procedimentais mencionadas, pode-se chegar à perspectiva que se segue.

Na primeira etapa, de detecção das normas em conflito, verifica-se a colisão do princípio da separação dos Poderes, apontado pela suposta violação decorrente da determinação judicial, para que o Executivo implemente direito fundamental, e completando o embate, o princípio da dignidade da pessoa humana, caracterizado pela garantia de assistência judiciária gratuita e integral aos que dela necessitarem.

Na segunda etapa, deve ser analisada a interação social dos fatos constitutivos da lide, no contexto social e jurídico na qual estão inseridos. Como foi demonstrado anteriormente, o município Demerval Lobão é uma localidade pobre, com acesso restrito aos serviços públicos e baixo índice de desenvolvimento humano, com significativa parcela da população analfabeta. Essas características (localidade pobre com alto índice de analfabetismo) fazem com seja imprescindível a instalação de Defensoria Pública permanente, para concretização do primado da assistência jurídica integral aos pobres.

Em terceiro momento, cabe o sopesamento dos elementos citados nas etapas anteriores, para a tentativa de obtenção da conclusão mais acertada. Analisa-se nesse momento, qual preceito prevalecerá no caso concreto, e se o Judiciário deverá permanecer inerte quanto à pretensão formulada na lide, preservando a distância entre os Poderes instituídos, ou se o Judiciário deve preencher a lacuna oriunda da ineficiência do ente federativo.

43 BARROSO, L. R. Curso de direito constitucional contemporâneo. 3 ed. São Paulo: Saraiva, 2011. p. 359. 
SOUZA, Fernando Machado de e CHUEIRI, Miriam Fecchio. Controle judicial do orçamento público para efetivação de direitos fundamentais. Revista Eletrônica Direito e Política, Programa de PósGraduação Stricto Sensu em Ciência Jurídica da UNIVALI, Itajaí, v.10, n.3, 2o quadrimestre de 2015. Disponível em: www.univali.br/direitoepolitica - ISSN 1980-7791.

\section{CONSEIDERAÇÕES FINAIS}

Ficou demonstrado que a complexidade dos valores constitucionais que dão sustentação estrutural ao Estado Democrático de Direito pode ocasionar a colisão entre os variados valores e normas que orbitam em torno da Constituição.

Dentre esses valores, de acordo com o primeiro acórdão mencionado, estão a separação dos Poderes institucionais do estado, que assegura a tripartição das competências estatais, admitindo, entretanto, a intervenção eventual e específica de um Poder em outro, para preservação do equilíbrio das competências primárias.

Dentre os freios e contrapesos enunciado, destaca-se o controle judicial da Administração, que em sede de jurisdição una, assegura o manto protetor da jurisdição a qualquer lesão ou ameaça de lesão, permitindo que o Judiciário dê a última consideração acerca dos atos praticados pela Administração.

Foi estabelecido o limite do controle do Judiciário, apresentando-se a já sedimentada possibilidade de análise da atuação administrativa somente de legalidade, reservando-se o administrador, a inviolabilidade dos atos decorrentes do mérito administrativo.

Em movimento de delimitação do conteúdo, foi apresentada a dignidade da pessoa humana, como vetor hermenêutico da atuação do Estado, devendo esta servir de baliza para a instituição de políticas públicas para promoção dos direitos fundamentais.

Nesse passo, fica demonstrada a possibilidade controle judicial da atuação administrativa, não somente dos elementos vinculados do ato administrativo, mas ampliando-se de modo a controlar finalisticamente a Administração, para que esta concretize direitos constitucionalmente assegurados.

Uma das modalidades de controle da fundamentalidade da atuação do Estado, se dá pelo controle do orçamento público. Nessa esteira, pode o Judiciário obrigar o 
SOUZA, Fernando Machado de e CHUEIRI, Miriam Fecchio. Controle judicial do orçamento público para efetivação de direitos fundamentais. Revista Eletrônica Direito e Política, Programa de PósGraduação Stricto Sensu em Ciência Jurídica da UNIVALI, Itajaí, v.10, n.3, 2o quadrimestre de 2015. Disponível em: www.univali.br/direitoepolitica - ISSN 1980-7791.

Executivo a adotar uma postura positiva frente á determinada ocorrência, ou ainda a contingenciar os recursos necessários, vinculando previamente na lei orçamentária as diretrizes concretizadoras de direitos fundamentais.

No caso analisado, justifica-se a atuação jurisdicional, pois ainda que, em decorrência de limitação orçamentária no exercício corrente, pode o estado adotar medidas cautelares de efetivação do mencionado direito fundamental, como por exemplo, a designação de defensor público na comarca de forma provisória, até que seja contingenciado na lei orçamentária a ser aplicada no ano seguinte, os recursos necessários para instalação das dependências físicas e provimento efetivo de membro da Defensoria na comarca.

Portanto, não constitui ingerência lesiva a atuação do Poder Judiciário, quando este determinar a efetivação de política pública garantidora de pressuposto fundamental, cabendo ao Judiciário intervir sempre que o Executivo, Portanto não constitui ingerência lesiva a atuação do Poder Judiciário, quando este determinar a efetivação de política pública garantidora de pressuposto fundamental, por omissão específica do gestor público, frustar a realização plena de direitos fundamentais.

\section{REFERÊNCIAS DAS FONTES CITADAS}

ALEXY, R. Teoria dos direitos fundamentais. Malheiros: São Paulo, 2008.

ALVIM, A. Manual de direito processual civil, volume 1: parte geral. 12 . ed. rev., e atual. São Paulo: Editora Revista dos Tribunais, 2008.

BARROSO, L. R. Curso de direito constitucional contemporâneo. 3 ed. São Paulo : Saraiva, 2011.

BRASIL, CONSTITUIÇÃO. Constituição da República Federativa do Brasil. Promulgada em 8 de outubro de $1988 .<$ http://www.planalto.gov.br/ccivil_03/constituicao/constituicao.htm>, acesso em 12 de agosto de 2014.

BRASIL, Lei Complementar n. 132. Altera dispositivos da Lei Complementar no 80, de 12 de janeiro de 1994, que organiza a Defensoria Pública da União, do 
SOUZA, Fernando Machado de e CHUEIRI, Miriam Fecchio. Controle judicial do orçamento público para efetivação de direitos fundamentais. Revista Eletrônica Direito e Política, Programa de PósGraduação Stricto Sensu em Ciência Jurídica da UNIVALI, Itajaí, v.10, n.3, 2o quadrimestre de 2015. Disponível em: www.univali.br/direitoepolitica - ISSN 1980-7791.

Distrito Federal e dos Territórios e prescreve normas gerais para sua organização nos Estados, e da Lei no 1.060, de 5 de fevereiro de 1950, e dá outras providências. <http://www.planalto.gov.br/ccivil_03/leis/lcp/Lcp132.htm>, acesso em 12 de agosto de 2014.

BRASIL. Apelação e Reexame Necessário No 70058249905, Sétima Câmara Cível, Tribunal de Justiça do RS, Relator: Sandra Brisolara Medeiros, Julgado em 24/07/2014) (TJ-RS - REEX: 70058249905 RS, Relator: Sandra Brisolara Medeiros, Data de Julgamento: 24/07/2014, Sétima Câmara Cível, Data de Publicação: Diário da Justiça do dia 29/07/2014. Disponível em: JUSBRASIL. http://tj-rs.jusbrasil.com.br/jurisprudencia/130203540/apelacao-e-reexamenecessario-reex-70058249905-rs/inteiro-teor-130203550, acesso em 16 de agosto de 2014.

BRASIL. AI 739151 AgR, Relator(a): Min. ROSA WEBER, Primeira Turma, julgado em 27/05/2014, ACÓRDÃO ELETRÔNICO DJe-112 DIVULG 10-06-2014 PUBLIC 11-06-2014

CAMBI, E. A. S. Neoconstitucionalismo e Neoprocessualismo. 2 ed. Revista dos Tribunais: 2012.

CARVALHO FILHO, J. dos. S. Manual de Direito Administrativo. 27. Ed. rev. ampl. e atual. São Paulo: Atlas, 2014.

CHIOVEndA, J. Derecho Procesal Civil. Principios. Tijuana: Cardenas Editor y Distribuidor, 1989.

GIACOMONI, J. Orçamento Público. 15. ed. ampl. rev. e atual. São Paulo: Atlas, 2010.

JUSBRASIL. http://tj-rs.jusbrasil.com.br/jurisprudencia/130203540/apelacao-ereexame-necessario-reex-70058249905-rs/inteiro-teor-130203550, acesso em 16 de agosto de 2014.

MARINONI, L. G. Técnica processual e tutela dos direitos. 2 ed. ver. e atual. São Paulo: Editora Revista dos Tribunais, 2008.

MELLO, C. A. B. de. Curso de Direito Administrativo. 31. ed. rev e atual. São Paulo: Malheiros, 2013

SARLET, I. W. A eficácia dos direitos fundamentais. 6 ed. rev. Atual. e amp. Porto Alegre: Livraria do Advogado, 2006.

Submetido em: Maio/2015

Aprovado em: Julho/2015 